\title{
Numerical simulation of bedload tracer transport associated with sand bar formation, bank erosion, and channel migration
}

\author{
Toshiki Iwasaki ${ }^{1}$, Satomi Yamaguchi $^{1}$, and Hiroki Yabe $^{1}$ \\ ${ }^{1}$ Civil Engineering Research Institute for Cold Region, 1-34 Hiragishi 1-jo 3-chome, Toyohira-ku, \\ Sapporo, Japan
}

\begin{abstract}
An understanding of bedload transport processes is an essential research goal for better prediction of river morphology and morphodynamics as well as the transport and fate of sediment-bound materials in river systems. Passive tracer particles have been used widely to monitor bedload transport processes in rivers by measuring the spatiotemporal distribution of the bedload tracers. Here, we propose a numerical model for reproducing the transport of bedload tracers in river systems, more specifically, the behaviours of bedload tracers under the influence of complex river morphodynamics. A two-dimensional morphodynamic model is combined with a flux-based bedload tracer model with use of the active layer approach. The model is applied to a laboratory experiment that demonstrates the transport processes within the channel of bedload tracers supplied from the floodplain. The numerical model effectively reproduces the main features of the experiment, namely, the bedload tracers supplied from the floodplain due to bank erosion deposit onto sand bars developed within the channel. Because the sand bars cause a very long residence time of the bedload tracers within the bed, the transport speed of the tracers is slowed significantly under the influence of bar formation and channel migration.
\end{abstract}

\section{Introduction}

An understanding of bedload transport processes is essential for predicting river morphology and morphodynamics, as well as the transport and fate of sediment-bound materials such as pollutants and organic matter in river systems. Direct measurements of bedload transport processes are still quite difficult, especially at the field scale, but several novel attempts have been made in last few decades. One such challenge is the use of passive tracer particles, which do not affect bedload transport but are distinguishable from the ambient bedload particles [e.g., 1, 2]. Tracking marked bedload particles provide information useful for identifying the bedload transport characteristics, such as travel distance and residence time of bedload particles [e.g., 3]. Additionally, the spatiotemporal change of deployed bedload tracer particles is interpreted in terms of advection-dispersion, representing how fast and how far bedload sediment can be transported in river systems [e.g., 4]. However, some difficulties exist in monitoring the behaviours of bedload tracers, especially at long time scales, because some of the tracers are lost due to deep burial or escape the reach of interest. 
Numerical modelling for tracking bedload tracer transport has been proposed [e.g., 5, 6, 7] and is a powerful tool for understanding river morphodynamics and substance dynamics. A numerical model can provide full information of spatiotemporal change of bedload tracers through a long time scale, which is generally difficult to obtain from measurement. However, application of such models to complex situations in rivers, such as under the effect of river morphodynamics, is still limited, even though river morphologies and their morphodynamics have important roles in large-scale bedload transport [8].

In this study, we perform a numerical simulation of the bedload tracer transport associated with complex river morphodynamic processes. More specifically, we numerically simulate the behaviour of bedload tracers that are supplied from a floodplain due to bank erosion within a channel under the effects of sand bar formation and channel migration. The numerical result is validated qualitatively with a laboratory experiment [9], and we show how the complex bed morphodynamics affect the bedload tracer transport.

\section{Numerical model}

The numerical model that we used in this study consists of a hydrodynamic module, morphodynamic module, and tracer transport module. A two-dimensional, unsteady, shallow water flow model with Manning's roughness coefficient to determine the bed shear stress is used to calculate the flow field, and an equilibrium-type bedload transport model is applied. A simple slope collapse model based on the angle of repose is incorporated into the morphodynamic model to include the effect of bank erosion. The governing equations are discretised on the staggered grid system, and the discretised equation is essentially solved by finite difference scheme. A splitting technique is used to numerically solve the momentum equation of flow. We use CIP method to solve the advection term of the momentum equation of flow. Detailed explanation and applications of this morphodynamic model can be found in the literature $[10,11]$. The morphodynamic model used here is generally sufficient for resolving the complexity of river morphodynamics, namely, sand bar formation, bank erosion, and channel migration, on which we focus in this study.

Despite a number of applications of this type of morphodynamic model to river morphodynamics [12], few attempts have been made to incorporate a bedload tracer model into the morphodynamic model. Nevertheless, it is well known that river morphologies and their dynamics have remarkable effects on the transport of bedload tracers [8] and thus have important implications for the transport and fate of sediment-bound substrates (e.g., pollutants, organic matter, etc.) $[13,14]$. A numerical morphodynamic model including a bedload tracer model will be able to contribute to understanding the interactions of river morphodynamics and bedload transport. Here, we use a flux-type bedload tracer transport model with the active layer approach to track and store the tracer distribution in the river bed. In the flux-based bedload transport model, the bed evolution is calculated by the Exner equation as follows:

$$
\left(1-\lambda_{p}\right) \frac{\partial \eta}{\partial t}+\frac{\partial q_{b x}}{\partial x}+\frac{\partial q_{b y}}{\partial y}=0
$$

where $t$ is the time, $(x, y)$ are the streamwise and spanwise coordinates, $\eta$ is the bed elevation, $\lambda_{p}$ is the porosity of the bed, and $\left(q_{b x}, q_{b y}\right)$ are the bedload transport rate in the $x$ and $y$ directions. The bedload transport rate is calculated by an equilibrium type bedload transport formula [15], which uses the local bed shear stress as a controlling factor on the transport rate. By using the active layer model [16], we also can obtain the flux-based bedload tracer transport model [e.g., 5] as follows: 


$$
L_{a} \frac{\partial f_{a}}{\partial t}+f_{I} \frac{\partial \eta}{\partial t}+\frac{1}{1-\lambda_{p}}\left(\frac{\partial f_{a} q_{b x}}{\partial x}+\frac{\partial f_{a} q_{b y}}{\partial y}\right)=0,
$$

where $L_{a}$ is the thickness of the active layer, $f_{a}$ is the fraction of bedload tracers in the active layer, and $f_{I}$ is the fraction of bedload tracers between the active layer and the substrate, which is dependent on the bed evolution (i.e., aggradation or degradation) as follows:

$$
f_{I}=\left\{\begin{array}{ll}
f_{a} & , \frac{\partial \eta}{\partial t}>0 \\
f_{t} & , \frac{\partial \eta}{\partial t}<0
\end{array},\right.
$$

where $f_{t}$ is the fraction of bedload tracers in the substrate layer. For solving the Eq. (2), $5^{\text {th }}$ order WENO scheme is used to reduce the numerical diffusion of tracers. In essence, since the model treats the sediment as uniform sediment, tracer transport model derived from the active layer approach has no effect on the bed morphodynamics. Instead, the tracer model obtains some information regarding the transport processes of bedload particles, namely, how the bedload is transporting in the calculation [e.g., 17].

The flux-based model for tracking the transport of bedload tracers has a limitation in capturing particle-scale bedload dispersions (e.g., streamwise dispersion [18], cross-stream dispersion [19], and vertical dispersion [20]) because stochastic characteristics of bedload motion are not considered at all in this framework. On the other hand, when bed evolution processes (e.g., channel formation, sand bar development, and bedform development) have dominant roles in the transport and dispersion of bedload tracers, the flux-based model is able to capture the large-scale tracer dispersion [17]. This is the case because the bed morphodynamics themselves have some stochastic effects (e.g., bar wavelength and height) on bedload transport. Therefore, if a numerical model with the use of the flux-based approach self-resolves the stochastic features of river morphodynamics, the flux-based model would be expected to be able to obtain a reasonable performance for the bedload tracer transport.

\section{Results}

The numerical model explained above was applied to a laboratory scale experiment regarding the bedload tracer transport associated with sand bar formation, bank erosion, and channel migration [9] to understand the model performance. Here, we briefly introduce the experimental setup and the main findings of the experiment.

Figure 1 shows the initial geometry of the channel and floodplain as well as the location of the initially deployed marked sediment tracers in the experiment. The length of the flume was $25 \mathrm{~m}$, and the total width of the flume was $3 \mathrm{~m}$. A straight channel (width of $0.5 \mathrm{~m}$ and bank height of $0.04 \mathrm{~m}$ ) was set within the flume, and the coloured tracer particles were installed in a portion of the floodplain. The initial slope of the channel and floodplain was set to 0.01 , and uniform sediment with a grain size of $0.76 \mathrm{~mm}$ was used. A steady water discharge of $2.76 \mathrm{l} / \mathrm{s}$ and an equilibrium bedload transport rate were provided from the upstream end. The initial water depth within the initial channel is approximately $1.4 \mathrm{~cm}$, resulting in the Froude number of 1.2. The bed and floodplain morphodynamics as well as the subsequent tracer behaviour were recorded using a digital camera. 


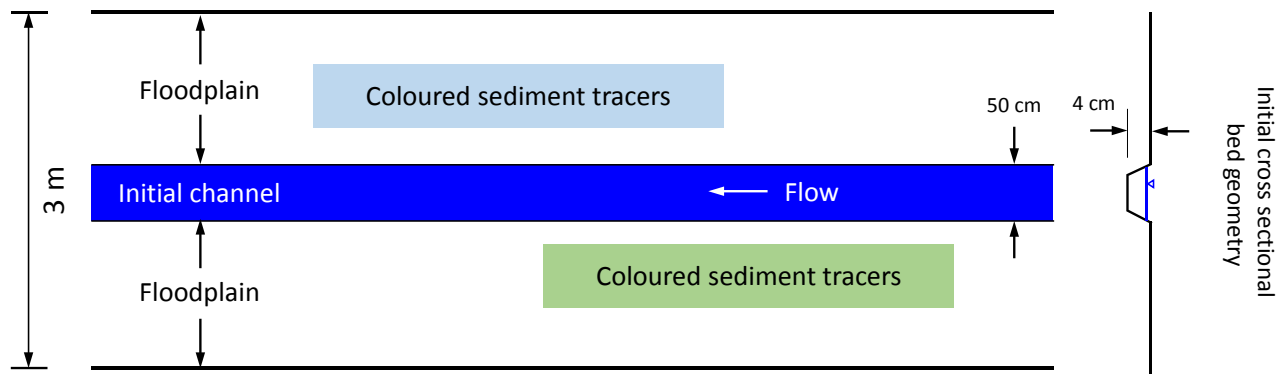

Fig. 1. Initial condition of channel and floodplain geometry and distribution of sediment tracer.
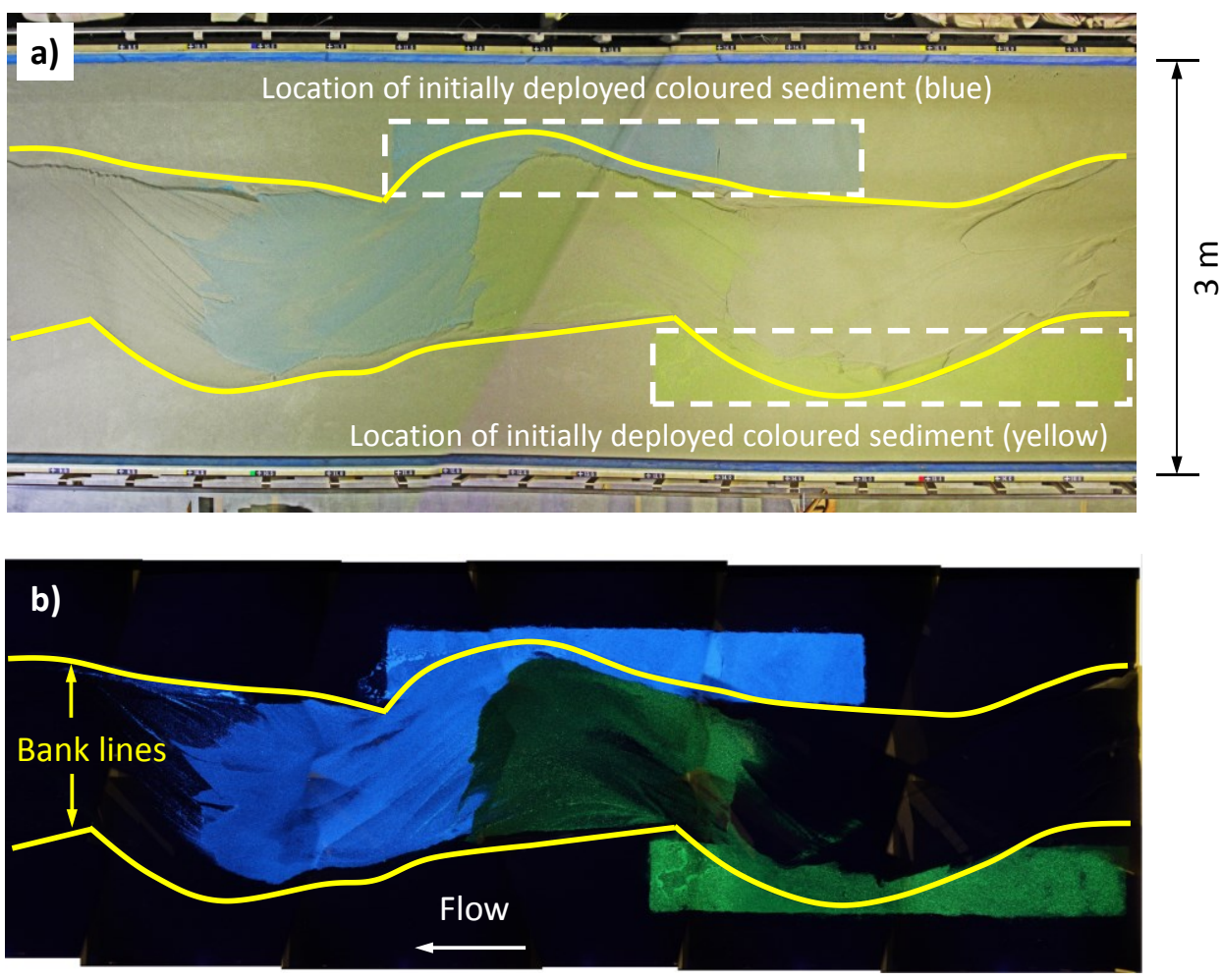

Fig. 2. Experimental results of bed evolution and distribution of marked bedload tracers. a) Top view of the reach of interest and location of initially deployed coloured sediment (tracers), and b) planimetric tracer distribution emphasised by using a black light [9]. This is a snapshot taken after 4 hours of experimental run.

Figure 2 shows the morphological changes of the bed surface and the associated bedload tracer distribution observed in the experiment. In the early stage of the experiment, alternate bars formed in the initial channel. The alternate bars subsequently caused erosion of the floodplain, resulting in the formation of a meandering channel. When this meandering channel was amplified enough to erode the tracer sediment deployed on the floodplain, the bedload tracers were supplied into the channel region. As shown in Fig. 2, the supplied bedload tracers were deposited onto large sand bars developed within the channel and so were not transported long distances downstream. This suggests that for the short time scale, large sand bars developed in the channel store most of the sediment supplied from the flood- 


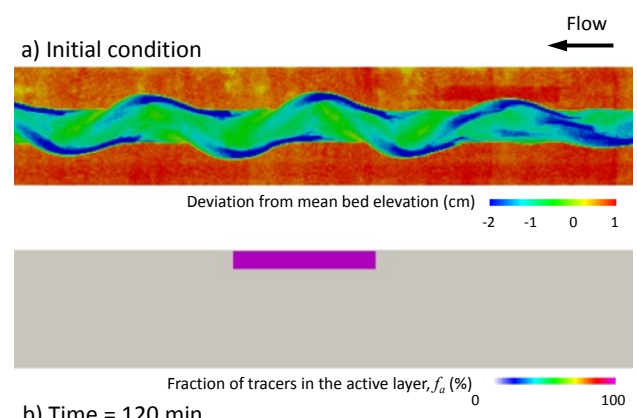

b) Time $=120 \mathrm{~min}$
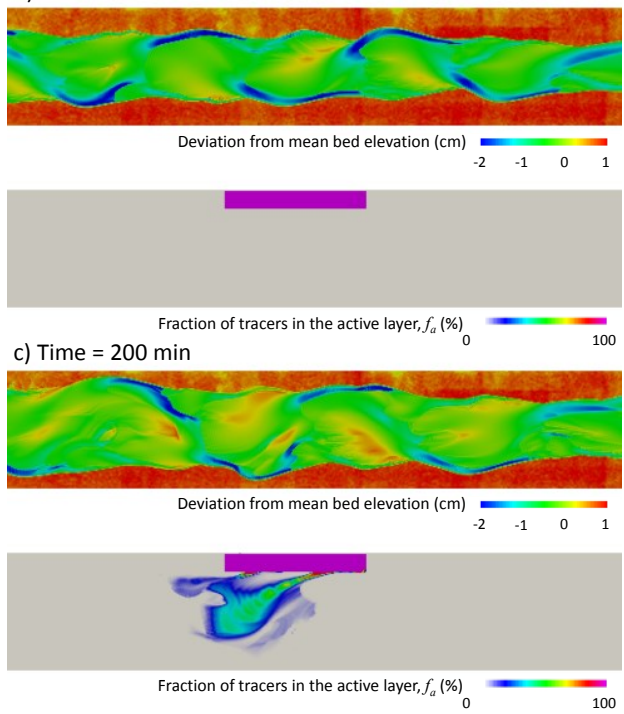

d) Time $=260 \mathrm{~min}$

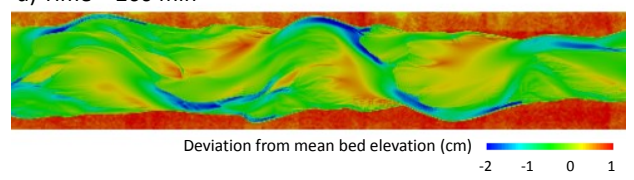

e) Time $=340 \mathrm{~min}$
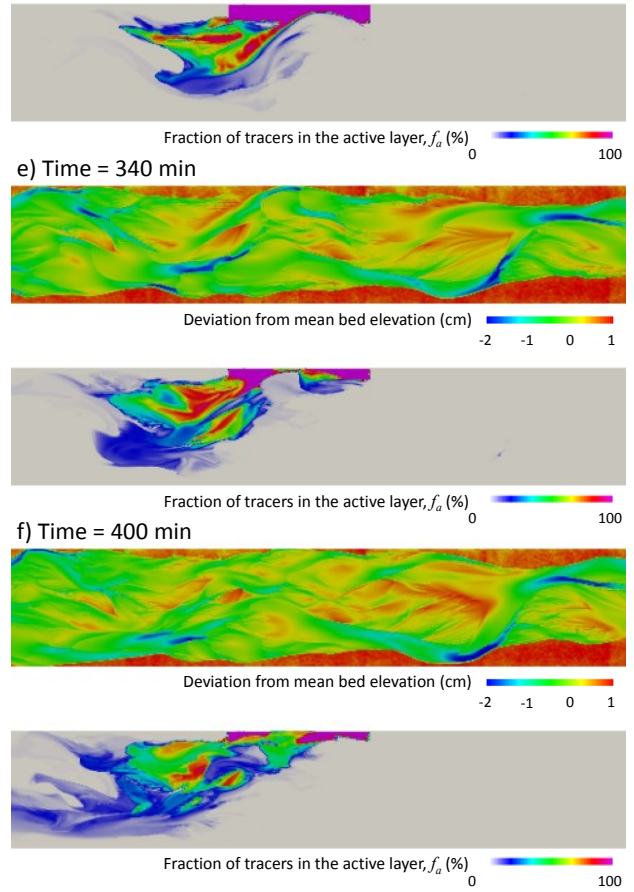

Fig. 3. Time series of simulated morphological changes of bed and associated bedload tracer transport.

plain due to bank erosion. By tracking the transport behaviours of the tracer, we can clearly understand the relationships between sediment transport and bed morphodynamics.

We then numerically reproduced the observed bed morphodynamic features and tracer transport behaviours described above using the proposed morphodynamic and tracer transport model. The numerical conditions were set to mimic the experimental conditions. The initial bathymetry was obtained using the measured bed and floodplain geometry after 1 hour of experimental run. The initial bed and tracer distribution given in the numerical simulation are shown in Fig. 3a. The size of the computational grid was set to $2.5 \mathrm{~cm}$ for both the $x$ and $y$ directions. The active layer thickness was set as twice the sediment grain size, and the thickness of substrate layers was set as $1 \mathrm{~cm}$. Although the morphodynamic model that we used in this study could sufficiently capture the main features of sand bar formation and channel evolution observed in the experiment, it was still difficult to reproduce the exact bed and channel morphologies observed in the experiment. This is in part attributable to the uncertainty of the bed and channel morphodynamics, as well as to the use of a simple bank erosion model. This constrains the model validation to the qualitative level; however, as we show below, the model was able to capture the overall tendencies of the morphological changes of bed and channel as well as the behaviours of the bedload tracers.

Figure 3 shows time series of the simulated morphological changes of bed and channel and the fraction of bedload tracers in the active layer. In the early stage of the simulation (Fig. $3 \mathrm{~b}$ ), alternate bars develop within the main channel, causing the development of a 
meandering channel. This development of meandering widens the channel region, and the meandering channel eventually reaches the tracer sediment that was initially installed in the floodplain (Fig. 3c). As discussed above, the tracer sediment supplied from the floodplain due to bank erosion only deposits onto scroll bars developed in the channel. Because the sand bars capture a large amount of the tracer sediment, the bedload tracers can travel only a short distance, which can be scaled by the length of the bars. The comparison between the experimental result (Fig. 2b) and the simulated bed geometry and bedload tracer distribution (Fig. 3d) suggests that the proposed model can qualitatively reproduce the main features of bed morphodynamics and associated tracer transport.

The experiment focused on relatively short time (i.e., initial meandering development) morphological change of bed morphodynamics and associated tracer transport. However, further long-term computation can provide additional insight into the long-term bedload tracer behaviour caused by the complex bed and channel morphodynamics. Figure $3 \mathrm{f}$ shows the simulated bedload tracer distribution resulting from long-term bed and channel morphodynamics. The dominant bed morphology in this stage is multiple bars, rather than the alternate bars and meandering channel observed in the early stage of the calculation (Fig. $3 \mathrm{~b}-\mathrm{d}$ ). Despite this significant change of bed morphology, the bedload tracers once stored in sand bar hardly transport downstream. For transport of such deposited bedload tracers to occur, the sand bars capturing the tracers need to be eroded by active bed morphodynamics. Such re-entrained bedload tracers will be captured again by sand bars developed in the downstream reach and will reside for a long time on the bed. This numerical result suggests that the time scale of bedload tracer transport in this situation is strongly governed by the bed and channel morphodynamics. The active sand bar development and the channel migration strongly reduced the advection speed of the bedload tracers toward the downstream reach. This occurred because the active morphodynamic processes stored the tracer particles in the substrate, resulting in a very long residence time of tracer particles.

\section{Conclusions}

In this study, we performed a numerical simulation of the transport processes of bedload tracers strongly influenced by complex river morphodynamics, i.e., sand bar formation, bank erosion, and channel migration. We first described a model framework based on a flux-based model for pursuing river morphodynamics and bedload tracer transport [17]. The model was tested with a laboratory experiment [9] that focused on the effects of river morphodynamics on the bedload tracer transport. The model could reasonably capture the main features of the bed morphodynamics and the bedload tracer behaviour observed in the experiment, namely, bedload tracers supplied from the floodplain due to bank erosion only deposited onto scroll bar. Further long-term computation suggested that the active bed and channel morphodynamics have dominant effects on the long-term bedload transport processes, namely, very slow downstream transport velocity due to long residence time of bedload tracers within sand bars.

The proposed model may be a potential tool for understanding and predicting the transport and fate of bedload tracers associated with such complex river morphodynamics. However, bedload transport mechanics not taken into account in the proposed model may also have important effects on tracer transport processes. For instance, inclusion of the effect of particle-scale bedload dispersion [18, 19, 20] might be of value for further research. In addition, detailed measurements of the spatiotemporal distribution of bedload tracers at small and field scales will be necessary for a more detailed validation of the numerical model. 


\section{References}

1. H.A. Einstein. Der geschiebetrieb als wahrscheinlichkeitsproblem, Mitteilungen der Versuchsanstalt für Wasserbau, Hydrologie und Glaziologie an der Eidgenössischen Technischen Hochschule Zürich, pp. 1-111, Rascher \& Co., Switzerland (1937)

2. R.I. Ferguson and T.B. Hoey. Long-term slowdown of river tracer pebbles: Generic models and implications for interpreting short term tracer studies, Water Resour. Res., 38(8), 1142, doi:10.1029/2001WR000637 (2002)

3. C.B. Phillips, R.L. Martin and D.J. Jerolmack. Impulse framework for unsteady flows reveals super-diffusive bed load transport, Geophys. Res. Lett., 40, 1328-1333, doi : 10.1002/grl.50323 (2013)

4. W. Sayre and D. Hubbell. Transport and dispersion of labeled bed material, North Loup River, Nebraska, U.S. Geol. Surv. Prof. Pap., 433-C, 48pp (1965)

5. G. Parker, C. Paola and S. Leclair. Probabilistic Exner sediment continuity equation for mixtures with no active layer, J. Hydraul. Eng., 126(11), 818-826, doi:10.1061/(ASCE)0733-9429(2000)126:11(818) (2000)

6. D. Furbish, P. Haff, J. Roseberry and W. Schmeeckle. A probabilistic description of the bed load sediment flux: 1. Theory, J. Geophys. Res., 117, F03031, doi:10.1029/2012JF002352 (2012)

7. E. Lajeunesse, O. Devauchelle and F. James. Advection and dispersion of bedload tracers, Earth Surf. Dynam. Discuss., https://doi.org/10.5194/esurf-2017-57, in review (2017)

8. M.A. Hassan, H. Voepel, R. Schumer, G. Parker, and L. Fraccarollo. Displacement characteristics of coarse fluvial bed sediment, J. Geophys. Res. Earth Surf., 118, 155165, doi:10.1029/2012JF002374 (2013)

9. S. Yamaguchi, T. Kyuka, Y. Shimizu, N. Izumi, Y. Watanabe and T. Iwasaki. Influence of sediment dynamics in river channel on the channel change, J. of JSCE B1(Hydraulic Engineering), in Japanese (2018)

10. T. Iwasaki, Y. Shimizu and I. Kimura. Numerical simulation of bar and bank erosion in a vegetated floodplain: A case study in the Otofuke River. Adv. Water Res. http://dx.doi.org/10.1016/j.advwatres.2015.02.001 (2016)

11. T. Iwasaki, Y. Shimizu and I. Kimura. Sensitivity of free bar morphology in rivers to secondary flow modeling: Linear stability analysis and numerical simulation, Adv. Water Resour., 92, 57-72, doi:10.1016/j.advwatres.2016.03.011 (2016)

12. A. Siviglia and A. Crosato. Numerical modelling of river morphodynamics : Latest developments and remaining challenges, Adv. Water Resour., 93(A), 1-3, doi.org/10.1016/j.advwatres.2016.01.005 (2016)

13. E. Falkowska and T. Falkowski. Trace metals distribution pattern in floodplain sediments of a lowland river in relation of contemporary valley bottom morphodynamics, Earth Surf. Processes Landforms, 40, 876-887, doi:10.1002/esp.3680 (2015)

14. T. Iwasaki, M. Nabi, Y. Shimizu and I. Kimura. Computational modeling of ${ }^{137} \mathrm{Cs}$ contaminant transfer associated with sediment transport in Abukuma River, J. Environ. Radioact., 139, 416-426, doi:10.1016/j.jenvrad.2014.05.012 (2014)

15. E. Meyer-Peter and R. Muller Formulas for bedload transport, IAHSR, Report on the second Meeting, 3, 39-64 (1948)

16. M. Hirano. River bed degradation with armoring, Proc. Jpn Soc. Civ. Eng., 195, 55-65, in Japanese (1971). 
17. T. Iwasaki, J. Nelson, Y. Shimizu, and G. Parker. Numerical simulation of large-scale bed load particle tracer advection-dispersion in rivers with free bars, J. Geophys. Res. Earth Surf., 122, doi:10.1002/2016JF003951 (2017)

18. V. Ganti, M.M. Meerschaert, E. Foufoula-Georgiou, E. Viparelli and G. Parker. Normal and anomalous diffusion of gravel tracer particles in rivers, J. Geophys. Res., 115, F00A12, doi:10.1029/2008JF001222 (2013)

19. G. Seizilles, E. Lajeunesse, O. Devauchelle and M. Bak. Cross-stream diffusion in bedload transport, Phys. Fluids, 26, 013302, doi:10.1063/1.4861001 (2014)

20. A. Pelosi, R. Schumer, G. Parker and R. I. Feruson. The cause of advective slowdown of tracer pebbles in rivers: Implementation of Exner based master equation for coevolving streamwise and vertical dispersion, J. Geophys. Res. Earth Surf., 121, $623-$ 637, doi:10.1002/2015JF003497 (2016) 